decide whether such claim is justifiable. He discusses the evidences on which lakes may be regarded as of marine originhistorical, morphological, biological, and with regard to existing names. He then devotes considerable space to the discussion of the claims of lakes in all parts of the world to be regarded as of such origin; to the relations between salt- and fresh-water fauna ; and to a critical examination of the faunistic argument for the marine origin of existing inland lakes. $\mathrm{He}$ concludes that none of the arguments derived from the considerations referred to have a convincin - importance in deciding as to the marine origin of lakes. Dr. Credner is of opinion that the question can only be satisfactorily solved on the geological evidence furnished by the various lake region; ; and this argument he means to develop in a second part of this very valuable monograph.

DETAILS are to hand of the recent exploration of the Mobangi tributary of the Congo, by Capt. van Gèle, which add something to the results obtained by Mr. Grenfell Capt. van Gèle's journey was made at the end of 1886 , at the time when the river is in flood, and when the current of the rapids is most powerful. At no part was the water less than I 80 metre in depth, and the deepest did not exceed I I metres. Not far from the embouchure of the Mobangi, on the left ban's, $8^{\prime} 30^{\prime \prime} \mathrm{S}$. lat., $17^{\circ} 35^{\prime} \mathrm{E}$. long., there is a French station. Above this part the Mobangi measures 2500 metres in breadth, I I metres in depth in the centre, with a current at the rate of $I$ metre per second. At the 4 th degree N. just below the rapids, there is a breadth of 1230 metres, a depth of 7.50 metre ; and a current of 1.50 metre per sscond. Between these two points the breadth of the Mobangi constantly varies, never exceeding 4000 metres. Its waters are of a clear brown colour, and its general aspect much the same as that of the Congo, its channel studded with islands, and its banks wooded. The right bank is often marshy, while the left bank is frequently steep, and the neighbourhood hilly. The left bank is much more densely peopled than the right, which never has but a scanty population. On the left bank, especially above the 2nd degree of latitude, there is a rapid succession of villages, belonging to the Baati, the Monyembo, and the Montumbi. The pesple are well made and tall (mean height of men $\mathrm{I} \cdot 80$ metre), they are industrious, but at the same time inveterate cannibals. In all the course of the river which has been obierved, Capt. van Gèle did not notice any affluent of importance; the only three worth mentioning are the Nghiri on the left bank, and the Ibenya and the Lobay on the right. The Nghiri winds through a very marshy country, which probably occupies the place of the conjectural lake of that name. About $4^{\circ} \mathrm{N}$. lat., a mountain mass is met with, running in a north-east and south-west direction, through which the Mobangi must penetrate in making its way to the Congo, and here it is, as might be expected, that rapids are found. The river here is narrowed into a gorge, impassable at high water, but, $\mathrm{Mr}$. Grenfell assures us, quite passable at low water for a suitable steamer.

THE Argentines have been very active recently in the exploration both of Patagonia and of their section (the eastern) of Tierra del Fuego. In a communication which appears in Petermann's Mitteilungen, Ramon Lista gives some details of a journey which he made 'through the centre of tha large eastern island from Sebastian Bay to the Strait of Le Maire. $\mathrm{He}$ states that our notions of the surface and climate of this island have hitherto been entirely erroneous: it has been regarcled as inhospitable, barren, and uninhabitable; its rocky mountains covered with everlasting snow. This may be so with the west part of the land, bat M. Lista gives a different account of the region traversed by him. From Cape Espiritu Santo to Cape Peñas he found valleys of varying breadth, covered with luxuriant fodder plants, and abounding in rivers, some of which are navigable, and which come from a snow-covered region in the interior. South of this is found the region of Antarctic forests. Though not so rich in grass and water as the northern region, M. Lista states that it made a favourable impression on him. He saw a good deal of the native population, and collected considerable data as to their anthropology. Many other scientific observations were made by him on the geology, fauna, and flora of the country.

THE Carniola section of the German and Austrian Alpine Club has resolved to put up on the Old Posthouse at Wurzen, the favourite head-quarters of Sir Humphry Davy, a tablet to commemorate his services in making known the South-Eastern Alps of Austria, and in attracting visitors thither.
THE ROYAL SOCIETY CONVERSAZIONE.

$\mathrm{AST}$ week we referred to the conversazione of the Royal Society, held on Wednesday, the IIth inst. It was the best which has been given for many years. A large number of remarkable objects were exhibited, and an account of some of the most important of them may be of interest to our readers.

Prof. A. W. Ruicker exhibited lecture apparatus to illustrate the measurement of coefficients of expansion by means of Newton's rings. The rings are formed between a glass plate and the convex end of a glass cylinder. These are pressed together by a metal frame, the front and back of which are connected by tubes through which a current of water is passed. The rings are projected on a screen and expand or contract when the temperature of the water is altered. The apparatus was shown in operation.

Maps to illustrate the present state of the magnetic survey of the British Isles now in progress, with a set of instruments of the Kew pattern, which have been used in the survey, were exhibited by Profs. Thorpe and Rücker. (I) Large map showing the stations at which observations have been made, and the values of three maynetic elements, viz. the inclination, declination, and total force at all places for which the reduction of the observa'ions his been completed. The epoch of the survey is to be January I, 1836, but the values given are not as yet corrected for secular change, except in the case of stations in Scotland. (2) Three maps of Scotland showing the lines of equal dip and equal total force for 1837,1858 , and I886, and the lines of equal declination for $185^{8}$ and 1836 . Mr. C. V. Boys exhibited a radio-micrometer and spinning-pile, which is probably the most sensitive instrument for measuring radiant heat yet made. It consists of a movable circuit of copper, antimony, and bismuth hung by a quartz fibre in a strong magnetic field One-hundred-millionth of a degree is not beyond the possible limit of such an instrument. Prof. D'Arsonval made an ins rument essentilly the same in principle last year. This radio-micrometer was devised by the exhibitor without knowledge of M. D'Arsonval's, from which, however, it differs in important details. The on? exhibited is an experimental instrument only; but it is absut one hundred times as sensitive as a thermopile. The spinnin-pile is peculiar in that it will start itself and turn either way indifferently when a spark is held on one side, and will at once stop when the spark is held on the other. Mr. Boys also showed an apparatus for shooting threads of glass, emerald, quartz, \&c. A thin rod of the material is fastened to the tail of an arrow and heated at the end by an oxy. hydrogen flame. The trigger of a cross-bow is immediately pulled, and the arrow shot, when a thread of extreme fineness is drawn out. These threads are far finer than spun glass, and many are finer than spider-lines. Threads of quartz are practically free from elastic fatigue, and are most suitable for the torsion threads of instruments of precision. Quartz can be drawn so fine that the thinnest parts are beyond the power of any possible microscope to define them. Experiments were made, showing the discharge by flame of electrically-spun threads.

Sir John Fowler and Mr. B. Baker exhibited a series of most marvellous photographs of the I 700 -feet span cantilever bridge now in course of construction across the Firth of Forth. Some of these photographs will be exhibited to-morrow at the Royal Institution. Specimens of wire and other articles made from "platinoid," manufactured by Mr. F. W. Martino, were exhibited by the London Electric Wire Company. Platinoid is untarnishable under atmospheric influences, and is specially suited to be a substitute for platinum-silver, German silver, \&c., for electrical purposes, as by experiments it has proved itself unchanged under variation of temperature (see Proceeding; of the Royal Society, No. 237, 1885). Major H. S. Watkin exhibited a Watkin patent aneroid invented by himself, and manufactured by Mr. J. J. Hicks. It is well known that aneroids have been made of al sizes, from 3 feet to half an inch in diameter; the length of the divisions on the scale representing inches on the mercurial barometer have also been varied to suit different purposes; but inasmuch as there was only one circle of figures, either the number of inches, and therefore the extreme height at which the instrument was available, had to be restricted, or the dimensions of the scale contracted in order to obtain a longer range. Major Watkin's patent index gets over this difficulty, and an open scale can now be obtained, combined with great length of range. Thus, in the 4 -inch patent aneroid $\mathbf{I}$ inch on the mercurial barometer can be made to represent fron 4 to 10 inches, and yet be available for great heights. 
Captain Wharton, Hydrographer of the Admiralty, exhibited a sun-signalling apparatus, designed by Mr. F. Galton, F.R.S., for the use of naval surveyors. The optical arrangements are the same as those described by him in the Journal of the British Association, 1858, but the movements are new. Its advantage is the facility it affords for accurate direction of the beam of light; an image of the sun appearing over the object to which it is desired to flash, when viewed through the telescope. Capt. Wharton also showed a set of charts illustrating the hydrographical conditions of coral reefs and islands that stand in deep water; a new chart of the south circumpolar regions, with tracks of eyplorers; and a chart showing sea-surface temperatures obtained off the north-west coast of Spain, June to Septemter I886. An improved pneumatic tide-gange or levelindicator was exhibited by Capt. de Wolski. This enables the registering apparatus to be at any distance, horizontal or vertical, from the spot in the sea below low-water mark where the tide is measured. Specimen charts (of which we have already given some account), exbibiting the conditions of weather over the Atlantic Ocean at the four seasons of the year, were shown by the Meteorological Council. (I) Daily synchronous charts of the North Atlantic in spring, February 27 to March 4, r883. These charts show that an anticyclone lies over Western Europe, and the neighbouring part of the Atlantic, with much calm and fog prevailing at its centre; whilst the predominant winds in these islands are northerly and easterly, typical March weather. (2) Daily synchronous weather charts of the North Atlantic in stimmer, August 1 to 6,1882 . These charts exhibit the prevailing area of high barometrical pressure on the eastern side of the Atlantic, which is related to a prevailing north westerly wind at the entrance of the Channel, changing to north oft the coast of Portugal, and eventually merging in the northeast trade. (3) Daily synchronous weather charts of the North Atlantic, in autumn, October 9 to 14,1882 . The numerous small areas of low barometrical pressure over the sea on these charts, which appear at the time of year when the region of highest pressure is about to be transferred from the ocean to the land, seem to indicate what takes place during the change. Several small cyclonic systems are shown in the southern part of the area of high pressure which prevails over the Atlantic in about $30^{\circ} \mathrm{N}$. (4) Daily synchromous weather charts of the North Atlantic in winter, February 9 to 14, 1883. The part of the Atlantic north of $40^{3} \mathrm{~N}$. is affected by a large area of low pressure, of which the centre lies somewhere to the southward of Iceland. These conditions are usual in winter. Maps of the English dialect districts, with key, by Mr. Alexander J. Ellis, to illustrate bis "Existing Phonology of English Dialects," not yet published, were exhibited by the author. Mr. Frank Crisp exhibited tarly microscopes:-(I) Campani's microscope. No field lens, and probably the earliest microscope extant. (2) Pope Benedict's microscope. Belonged to Cardinal Lambertini, afterwards Pope Benedict XIV. Triple crown and cross keys inlaid in front of box. (3) Hooke microscope. This also belonged to the same Pope. (4) Oppelt's microscope. Instruments for measuring extensions and cumpressions in materials subjected to stress were exhibited by Prof. IV. C. Unwin. (I) Apparatus to measure extensions to $\mathrm{I} / \mathrm{I} 0,000$ of an inch. Two clips embrace the bar, so that the movement of the middle points is the mean of the extensions on both sides. The clips are set level by sensitive levels, and the distance between them is measured by a micrometer screw. (2) Apparatus to measure extensions. The bar is embraced by clips, so that a mean of the extensions on each side is taken. The extensions are measured by a roller and mirror. Measures to $1 / 100,000$ of an inch. (3) Similarly arranged apparatus for compressions. The strain is measured by a microscope micrometer. Measures $\mathbf{1} / 50,000$ of an inch. Apparatus for the drawing of automatic stress-strain curves was shown by Prof. Kennedy. In this apparatus the bar to be tested is extended "in series" with a much stronger har of steel. This bar is used as a spring, and its elastic extensions, magnified by a light pointer, are taken as proportional to the stress in the test-bar, and recorded by the end of the pointer on a sheet of smoked glass which has a motion at right angles to that of the points, and proportional to the elongation of the test bar. There is also a special arrangement of differential levers to eliminate any errors in this motion which might arise from the extension or "give " of other parts of the instrument.

Forty-six photographs of clouds in many parts of the world were exhibited by the Hon. Ralph Abercromby, by whom they were photographed. These were mostly taken during two voyages round the world for meteorological research. The pictures illustrate very clearly the identity of cloud-forms all over the world, for similar cumulus and cumulo-nimbus forms range in latitude from London to near Cape Horn-including one actually on the equator ; and the stratus from Sweden to New Zealand; while the mists in the Himalayas are indistinguishable in general character from those of Great Britain. In addition to illustrations from the countries above mentioned, clouds are represented from Teneriffe, Brazil, the Falkland Islands, the Indian Ocean, and Borneo. Model of high-speed hydraulic or steam engine for driving electric light, and other purposes, was exhibited in motion by Mr. Arthur Rigg, the inventor. Reciprocation of pistons, and other moving parts, imposes an early limit to speed in engines of ordinary construction, so it has long been an unsolved problem how to produce a satisfactory engine without this evil, no rotary engines having ever yielded results encouraging their adoption. The revolving engine possesses pistons and cylinders, which are the best mechanical contrivance for remaining steam tight or water tight, and these have reciprocations relative as between each other, but only rotation in relation to the earth, while the cylinders and pistons revolve each on their own independent centres. The static balance and the dynamic balance are iden. tical, and this engine therefore runs in equilibrium, without vibration, and in almost perfect silence. It is governed by varying the rate of expansion in the case of steam, or by varying the length of stroke in the case of water, and produces very economical results. It has none of that rhythmical variation in speed which occurs during each revolution of an ordinary engine. It is the only engine hitherto invented which can be driven at high speed by water pressures of considerable amount, and is found to give a perfectly steady incandescent light when making 250 revolutions per minute, driving a dynamo for 100 lamps, and worked by $700 \mathrm{lbs}$. per square inch water pressure. Prof Forbes's thermo-galvanometer, made by Messrs. Nalder Bros. and Co., was exhibited by Prof. George Forbes. This consists of a ring, half of antimony, half of bismuth, one of the soldered junctions being filed thin and blackened to receive radiations. The conductivity of the ring is increased by the addition of a block of copper. A light Thomson magnet and mirror, suspended by a silk fibre, is placed inside the ring. The present form of instrument is rendered astatic by means of a second magnet. Prof. Forbes also showed specimens of electric welding by Prof. Elihu Thomton, of Boston, U.S.A. Some of Dr. J. Puluj's remarkable vacuum tubes, made by Müller, of Bonn, were exhibited by Mr. Warren De la Rue, and Dr. Hugo Muiller. (I) Electrical radiometer with phosphorescent vanes. (2) Electrical radiometer with phosphorescent rotating disk. (3) Electrical radiometer with two phosphorescent rotating disks. (4) Electrical radiometer with rotating bell-glass. (5) Phosphorescent lamp. Specimens illustrating the effect of great earth-movements upon the pebbles contained in rock-masses were exhibited by Prof. J. W. Judd. (I) Series of impressed, faulted, crushed, and polished quartzite pebbles from the old red sandstone, near the great faul, Stonehaven, N.B. (2) Impressed limestone pebbles from the Swiss nagelflue (3) Faulted, crushed, and re-cemented fints from the chalk. (4) Pebbles from Bunter conglomerate, crushed and scratched by earth-movements. Specimens and microscopic sections of carboniferous chert, filled with spicules of siliceous sponges, were exhibited by Dr. G. J. Hinde. Beds of chert are largely developed in the carboniferous rocks of Yorkshire, North Wales, and Ireland, between the horizon of the carboniferous limestone and the millstone grit. In Flintshire they attain a maximum thickness of probably not less than 350 feet. These strata are of organic origin, and built up mainly of the detached skeletal spicules of siliceous sponges, which, for generation after generation, lived and died on the sea-bottom in these areas, and by the gradual accumulation of their microscopic spicules formed the rocks. Maps and sections of the Geological Survey of the United Kingdom were exhibited by Mr. Arch. Geikie, and a MS. geological map of the British Isles, for the geological map of Europe now in preparation by the International Geological Congress, was shown by Mr. William Topley, of the Geological Survey of England. Scale, I : 1,500,000 (I inch to $23 \frac{1}{2}$ miles). The map will te in forly-nine sheets, in all about 12 feet by 10 feet. The cost of producing the map is contributed by the various Governments of Europe. England's share of the expense is $£ 400$, instalments of which are given, as required, by the Royal Society from its Government grant. For this sum a hundred copies of the complete map will be sent to the Royal Society. A drawing of a specimen showing the assump- 
tion of antenniform characters by the crustaceous ophthalmite, received from M. Alphonse Milne-Edwards, was exhibited by Prof. G. B. Howes. Mr. C. Baker showed Dr. Carl Zeiss's apochromatic objectives and eye-pieces, made of the new Abbe-Schott glass. The "Secohmmeter," a direct reading instrument for the absolute measurement of the coefficients of self and mutual induction, and for the absolute measurement of a capacity, was exhibited by Profs. Ayrton and Perry. On a future occasion we shall have something to say about this instrument. $\mathrm{Mr}$. J. Norman Lockyer exhibited photographic comparison spectra of sun and metallic elements, taken at Kensington with Rowland grating. The metallic spectra were obtained in the usual way by putting metallic salts between the poles of an electric lamp. The lamp was placed at a distance of about 9 feet from the slit, and the rays of light diverging from it were rendered parallel by a lens of 9 inches focal length. An image of the sun was focused between the poles of the lamp by another lens of Io inches focal length placed between the siderostat and the lamp. The light from the sun was thus sent through the slit under exactly the same conditions as that from the arc, so that both were brought to the same focus. The slit was covered with a piece of paper having four tongues, one of which was turned back for each exposure. The exposures varied from five to ten minutes. $\mathrm{Mr}$. Lockyer also exhibited photographs of the spectra of compounds of carbon under various conditions, and a map showing the passage from flutings to lines in the spectrum of alcohol with increase of temperature, and the distribution of the various carbon flutings in the spectrum of tha electric arc. The photographs, especially those of carbon dioxide, show how the spectrum of each compound depends upon the conditions of temperature and pressure to which it was subjected. A comparison of the spectra of different compounds will also show the general relations which exist between them; it will be seen that some of the flutings are special to certain compounds, while others are common to all. The accompanying map (approximately to a wave-length scale) represented the changes in the spectra of alcohol vapour produced by changes of temperature and pressure. The part of the map to the right of 4900 was mapped from eye-observations, and the remainder from the photographs. The lower half of the map shows the distribution of the carbon flutings in the spectrum of the electric arc, the spectrum of each portion of the arc being represented on the same horizon. A point of great interest is the appearance, in the flame which surrounds the negative pole, of three sets of flutings which shade off towards the red. The two most refrangible flutings shown in the alcohol spectra are apparently coincident with two of the five-membered ultra-violet group occurring in the spectra of the arc and cyanogen. Photographs of stellar spectra taken at Harvard College by Prof. Pickering (Henry Draper Memorial) were also shown by Mr. Lockyer. Spectra of $\alpha$ Lyræ, $\beta$ Geminorum, $\alpha$ Cy yni, $\alpha$ Tauri. These have already been referred to in NATURE. Twelve-inch Indian sun photographs taken at Dehra-Dun, India, March 4 and May 2, I886, were exhibited by the Solar Physics Committee. The Rev. Dr. Pritchard showed (I) original negative of the Cluster in Perseus. Taken with the De la Rue reflector, 13 inches aperture; 120 inches focal length ; exposure 30 minutes ; diameter of plateholder $6 \frac{1}{2}$ inches. This is one of a series of photographs taken in order to ascertain the greatest angular extent of the field, in which all the star impresions are free from deformation of circular contour. All the stars on this plate, even to the angular points, at a distance of $80^{\prime}$ from the centre, are sensibly free from ellipticity. Positive enlargemen's on glass of the above. (2) The Macromicrometer presented by Dr. W. de la Rue to the Oxford University Observatory, carrying one cf the original negatives of 6r Cygni, as used for the determination of the parallax of the two components of that star. (3) Original negative showing the photographic genesis of star impressions formed during varying durations of exposure, and viewed under high magnifying power. Dr. Edgar M. Crookshank exhibited micro-organisms :- (I) Microscopical specimens, including living micro-organisms and permanent preparations. (2) Cultivations on nutrient jellies, potatoes, \&c., of the following microorganisms :-

Bacillus tuberculosis. Micrococcus tetragonus. Bacillus typhosus. Koch's comma-bacillus. Finkler's comma-bacillus. Deneke's commatilus. Emmerich's bacterium.
Staphylococcus pyogenes citreus. Streptococcus of erysipelas. Bacillus of anthrax. Micrococcus prodigiosus. Bacillus indicus. Bacillus of blue milk. Bacillus violaceus. Bacillus pyocyaneus.

Water-cultures of the garden bean (Vicia Faba), the roots of which are infested with tubercular swellings, due to the parasitic action of a fungus, the extremely minute germs of which are common in the soil, were exhibited by Prof. H. Marshall Ward. Dr. E. Klein exhibited microscopic specimens and culture-tubes of the microbe of (I) foot-and-mouth disease ; (2) scarlet fever ; (3) several different forms of septicæmia ; (4) swine plague.

\section{THE METEOR OF MAY 8.}

$\mathrm{N}$ Sunday evening, May 8, at $8 \mathrm{~h} .22 \mathrm{~m}$., hundreds of people witnessed the flight of the brilliant slow-moving fireball, about which three letters were printed in NATURE last week. At the time of its appearance daylight was still so strong that only Venus, Jupiter, Saturn, and a few first-magnitude stars were visible in the firmament. At stations in the ea itern part of England the fireball fell in the western sky; at Bristol and the west it descended in the east; while at Stafford it is described as falling in the south.

Descriptions of the apparent path and appearance of the meteor have been received from Eastbourne, Staines, Stafford, Hartfield near Tunbridge Wells, London, Clevedon, Bristol, \&c. It is referred to by most observers as a strikingly brilliant object, in comparison with which the planet Venus looked small and faint.

The following are quotations from some of the reports which have reached me from various places :-

The Rev. F. B. Allison, of Eastbourne, says :-_" An exceptionally bright fireball was seen to fall to-night [May 8] at $8 \mathrm{~b}$. 3om. There was so much light in the sky that I could only detect $\alpha$ and $\beta$ Aurigæ. The meteor was considerably larger and brighter than Venus, of a bluish tint, with train of sparks, slow motion : 6 seconds over the path indicated." Mr. Allison sends a diagram, in which the observed part of the course is shown extending under $\alpha$ and $\beta$ Aurigæ, at an angle of about $42^{\circ}$, to a length of about $24^{\circ}$.

Mr. Francis Gare, of Staines, writes :- "The fireball was observed about $8 \mathrm{~h} .20 \mathrm{n}$. to $8 \mathrm{l} .25 \mathrm{~m}$., and was about half the size of the moon ; its light was pale blue in colour, and was very bright, startlingly ${ }^{-}$so. It left a train of red sparks about $6^{\circ}$ long. The first part of its track was invisible to me as I was in a room with a S.W. window; this, too, would have prevented my hearing the detonation had there been any. The motion was slow." Mr. Gare sends a sketch, in which the fireball is represented as traversing $40^{\circ}$ at an angle of $38^{\circ}$, and terminating $10^{\circ}$ east of a line joining Venus and the horizon.

The Rev. E. Allen, of Castlechurch Vicarage, near Stafford, says:- "The time was within five minutes of $8 \mathrm{~h} .20 \mathrm{~m} .$, May 8 . It was so light that to see Spica as a reference-point, and whose place I knew exactly relatively to that of Jupiter, which was plainly visible, I had to fetch a binocular. The meteor was very large, and brilliantly white. Its light seemed to rise and fall in pulsations about two-fifths of a second in period, and its general power and effect was like what an extremely brilliant Roman candle ball would appear in somewhat deeper twilight at a distance of 50 or 60 yards from the spectator. Its motion was very slow, taking, I estimate, 5 seconds in passing along its total path of about $12^{\circ}$ of arc. Estimating proportions of distance by eye, with the space between Jupiter and Spica as a guide, the path was something as follows: It was inclined about $25^{\circ}$ to a perpendicular, the angle lying on the west, and fell from about R.A. $12 \mathrm{~h}$. $35 \mathrm{~m}$., Decl. $13{ }^{\circ} 30^{\prime} \mathrm{S}$, in a line nearly parallel to $\delta$ and $\zeta$ Corvi, and east of those stars."

At Hartfield, near Tunbridge Wells, the fireball was observed passing a little below Venus from right to left, and inclined $30^{\circ}$ or $40^{\circ}$ to the horizon. Duration, 3 or 4 seconds.

At Bristol, the meteor appears to have been pretty generally observed, and a large number of reports have come to hand. These, though differing in some essential particulars, sufficiently prove that the motion was from S.E. to E. by N. at an angle of $30^{\circ}$, the altitude at disappearance being about $20^{\circ}$. One observer describes it as being as large as a tennis-ball, and having a duration of 6 seconds. Another, who mentions the time as
Bacterium of rabbit septicæmi Bacillus of mouse septicæmi Bacillus of swine-erysipelas. Bacterium of pneumonia (Friedländer).

Staphylococcus pyogenes albus. Staphylococcus pyogenes albus.
Staphylococcus pyogenes aureus. 